\title{
Analyze of Students' Learning Outcomes Based On Mental Models of Atomic Structure
}

\author{
Abdul Majid ${ }^{1}$, Binar Kurnia Prahani ${ }^{2}$ \\ ${ }^{1}$ (Department of Chemistry Education, Mulawarman University, Indonesia) \\ ${ }_{2}^{2}$ (Department of Science Education, Sunan Ampel State Islamic University of Surabaya, Indonesia)
}

\begin{abstract}
This purpose of this research is to analyse students' learning outcomes based on mental models of atomic structure. Data were collected from test of mental model (i.e. perception test, imagination test, and discourse comprehension tests) and interview. Analyse data used descriptive method. Subject is 32 student of chemical education in academic years 2012/2013 of Mulawarman University. The results of this research were positive; 1. Mental model of perception has average value of 41.74 in moderate criteria. 2. Mental model of imagination has average value of 42.95 in moderate criteria. 3. Mental model of discourse comprehension has average value of 51.84 in moderate criteria. It shows that students' learning outcomes based on mental models of atomic structure in moderate criteria. Research findings is there are three students who had two mental models of perception and imagination. Due to mental models held by the students are expected to change because of its dynamic character.
\end{abstract}

Keywords: Atomic Structure, Discourse Comprehension, Imagination, Mental Models, Perception.

\section{Introduction}

Mental models are used to produce form of concept be more simple, provide simulation and support for visualization, as well as to provide the scientific phenomena. Mental models provide a framework for the interpretation of ideas and activities; assist in restructuring existing information and aid in the inculcation of new information. Mental models are deeply held internal images of how the world works, images that limit us to familiar ways of thinking and acting ${ }^{[1]}$. Mental models have very important influence on the development of scientific knowledge. Therefore, mental models have a central role in science. In recent years, a number of researchers have begun to test the effects of team mental models on team performance. These studies have documented the beneficial effects of team mental models on team task effectiveness ${ }^{[2-9]}$. While encouraging, these studies leave several questions unanswered. The results of recent studies suggest that team benefit when their members share similar mental models of the team's task ${ }^{[5]}$. The team mental model construct grew out of prior theory and research in cognitive psychology regarding individuals' mental model ${ }^{[10]}$. Rouse and Morris defined a mental model as a mechanism whereby humans generate descriptions of system purpose and form, explanations of system functioning and observed system states, and predictions of future system states ${ }^{[11]}$. Mental models are organized knowledge frameworks that allow individuals to describe, explain, and predict behavior ${ }^{[11,12]}$. Mental models specify relevant knowledge content as well as the relationships between knowledge components ${ }^{[9]}$. An individual's mental model was reflect the individual's perception of reality ${ }^{[13]}$. Accordingly, mental models vary in their accuracy and coherence ${ }^{[14-16]}$. Further, mental model accuracy is predictive of individual performance ${ }^{[17,18]}$. A number of theorists have adopted a cognitive perspective, suggesting that team mental model-defined as 'team members' shared, organized understanding and mental representation of knowledge about key elements of the team's relevant environment ${ }^{[19]}$ may enhance team members' coordination and effectiveness in performing tasks that are complex, unpredictable, urgent, and/or novel ${ }^{[2]}$. Team members who share similar mental models can, theorists suggest, anticipate each other's responses and coordinate effectively when time is of the essence and opportunities for overt communication and debate are limited ${ }^{[4]}$. In addition, teaching chemistry to build mental models requires a strategy that involves the use of chemical representations as mentioned above accurately to build a mental model of students requires an understanding of the three levels of chemical phenomenon.

Various research on mental models have shown very important to enhance the students' understanding of chemistry concept ${ }^{[20-23]}$. The use of concrete models, image representation, animation and simulation has proven beneficial for the students' process of understanding of chemical concepts, particularly the concept of molecular or submicroscopic level ${ }^{[24]}$. Some research on mental models have found that many students have a very simple mental model of chemical phenomena, for example atomic and molecular models which are depicted as discrete and concrete structures, but do not have the skills to build more complex mental model ${ }^{[22,25,26]}$. Several researches indicate that many factors can affect the ability of students to make connections between the three levels of chemical phenomenon in growing thinking skills ${ }^{[27-29]}$. Mental models are unstable 
and the student's ability to operate or use their mental models in order to explain the events that involve the use of a visual model is very limited, so the need for ongoing training to build it ${ }^{226 ; 30-32]}$.

The result of preliminary study in chemistry education of Mulawarman University, Indonesia was found problems in chemistry learning as following: (1). Students attend chemistry classes solely in order to pass. (2) the student attends learn not to increase knowledge. (3) Student's learning outcome in low criteria caused by low motivation in chemistry learning. (4) Students have limitation in mental models. Therefore, there are several solutions to improve student learning outcomes that learning process should be effective; students must take an active role in the learning process, the role of parents in teaching their children and society as a student learning. (i.e. chemistry learning based on mental model). The variables can build mental models of the students in between perception, imagination, and understanding discourse. Those variables are the elements of a mental model builder. Perception is a mental activity gives meaning (interpretation) of the information received by memory. Imagination is a cognitive process in which the elements in mental activity separated from sensory sensation. Imagination involves synthetic blends aspects of memory, memories, or experiences into different mental constructions. In addition to the perception and imagination, a person's mental models are also a function of the level of understanding of the discourse.

The purpose of this study is to analyse students' learning outcomes based on mental models of atomic structure. The following research questions were investigated:

1. How students' learning outcomes based on mental models of atomic structure?

2. How profile students' mental models (perception, imagination, and understanding discourse) of atomic structure?

\section{Method of Research}

This research used descriptive methods. Subject is 32 student of chemical education in academic years 2013/2014 of Mulawarman University. Data were collected from test consists of learning outcomes test and mental model tests (i.e. perception test, imagination test, and discourse comprehension tests) and interview. Analyse data used descriptive method. The study involved students as participants fill in a matter of form test questions. The test consists of learning outcomes test and mental model tests (i.e. perception test, imagination test, and discourse comprehension tests of atomic structure). Then the findings from these tests through analysis to determine the profile of a review study findings are based on student mental models.

Procedures of research as following: 1. Phase of preparation; this phase begins with the identification of students who experience learning outcomes in the atomic structure and mental models of atomic structure. 2 . Phase of implementation; in this research, a written test and interview on Chemical Education in Mulawarman University students who have studied the atomic structure at the school and campus. 3. Phase of analyse and evaluation; The final stage in this research is reporting research results which includes the processing and analyzing research data written test results, further discussion of the results of the analysis and concludes by drawing conclusions and giving advice.

\section{Result And Discussion}

\section{A. Students' Learning Outcomes Based On Mental Models of Atomic Structure}

The students' learning outcomes based on mental models of atomic structure have average value of students is 42.23 in moderate criteria. The result of this results supported by another research that various research on mental models have shown very important to enhance the students' understanding of chemistry concept $^{[20-23]}$. But over time the ability of the students to remember the material they have understood reduced. This is due to several factors (1) the lack of memory of students; (2) lack of interest in reading students; (3) the use of learning strategies are less effective. The learning environment will be successful if students have passion or motivation, understanding of the material that has been taught, good memory of the material that has been taught and use of strategies or methods appropriate to the learning process, thus increasing student understanding. The decline student results are due to the student experience as following (1). Students attend chemistry classes solely in order to pass. (2) Students attend learn not to increase knowledge. (3) Student's learning outcome in low criteria caused by low motivation in chemistry learning. (4) Students have limitation in mental models. Students' mental models of atomic structure as follows: (1) Mental model of atomic structure of perception has average value of 41.74 in moderate criteria; (2) Mental model of imagination has average value of 42.95 in moderate criteria. (3) Mental model of discourse comprehension has average value of 51.84 in moderate criteria. Mental models specify relevant knowledge content as well as the relationships between knowledge components ${ }^{[9]}$. From the analysis of learning outcomes based on student mental models can be said that the influence on learning. As a teacher you should know in advance the extent of students' understanding of the material that will be taught. Once it can be determined that the appropriate learning model that can help students to develop a mental model of the student in order to minimize the occurrence of incomprehension

DOI: 10.9790/7388-070101120124 www.iosrjournals.org $\quad 121 \mid$ Page


students the material to be taught. Selection of learning models tend to be difficult indeed to the class by the number of students that much. However, these obstacles can be reduced by equalizing students' perceptions of the material to be taught. Once you know the extent to which students understand the material to be taught. Then it can be determined that the appropriate learning model of student mental models besides student mental models can also be developed mental models of imagination and discourse of the students so that abstract concepts can be more easily understood. Lecturer is expected to explain clearly understanding the terms chemical that arise during the teaching material. As it is known that student have perception mental model in criteria moderate towards chemistry learning especially in atomic structure. This is related to how students understand the mental models of learning for students.

\section{B. Profile Students' Mental Models (Perception, Imagination, And Understanding Discourse) Of Atomic Structure}

Mental models are structures constructed knowledge of the individual to understand and explain the experience. Mental model like as a representation in the mind of real or imaginary situations. Mental models are organized knowledge frameworks that allow individuals to describe, explain, and predict behavior ${ }^{[11,12]}$. The definitions of mental models are so varied that basically has the same meaning that the mental model of a person can change because of the dynamic nature, the dynamic nature of the change and will usually be repaired when additional information. Due to the dynamic nature of mental models spawned a new terminology that mental model mix and pure mental models. A student may have more than one mental models at the same time, the students said to have a mental model of the mix when the phenomenon occurs when students have their own knowledge about a concept of chemistry that might go wrong and learn about the knowledge of chemical concepts that should be used, which means a mix of knowledge between self-knowledge and knowledge of others. While pure mental model is that if a student is always using his own knowledge without the need to listen to other people the knowledge or explanation. This means that a person is capable of holding two or more mental models that are not consistent. Mental models can be expressed through the writings and drawings. Based on this statement it is about a matter that is written is also accompanied by imagination has been linked to atomic structure. Instrument detection of mental models is the perception, imagination and discourse comprehension. The ability of perception, imagination and discourse comprehension is an attribute that can present a person's mental models.

\section{Profile students' perception of atomic structure}

Perception has meaning response (acceptance) directly from an absorption or process by which someone knows some things through the senses. Perception is process to interpreting information by using knowledge that has been stored in memory. Perception as the ways people interpret the information obtained based on understanding the individual. Based on these definitions can be understood that the perception can be interpreted as an interpretation of a person to an understanding of information based on an object. It is apparent occur different perception of objects the same, depending on the level of understanding and interpretation of each individual of the object ${ }^{[8,33]}$. And also the ability to perceive a model correctly play an important role in all disciplines, but most importantly in chemistry because many chemical phenomena explained by using a model of learning especially in atomic structure. In a matter of perception tests amounted to 8 multiple choice questions. In tests this matter is given a score if the answers are correct score of 1 if the answer wrong score of 0 . This test is useful to determine the ability of students to the beginning of the atomic structure of matter. From the results of this test are $79 \%$ of students who have a mental model of perception. It can be concluded that the number of students who have a mental model of perception on tests of mental models of this, for it was through this research professors are expected to explain to the students to use learning strategies appropriate as expository learning that emphasizes the process of delivery of material received verbally, with this strategy lecturers can determine the extent to which students master the material, this strategy can be used for a number of students and large class sizes. Therefore, before this strategy is applied first lecturer must formulate learning objectives are clear and measurable. It is very important to understand, because of the specific goals it possible to control the effectiveness of the use of learning strategies so that students can understand the material properly especially in atomic structure.

\section{Profile students' imagination of atomic structure}

We often misunderstand the meaning of the imagination. In reality, imagination is a sense of work in developing a broader idea of what's been seen, heard, and felt. With imagination, people develop something of simplicity to be more valuable in mind. To avoid misunderstanding, the writer explain a little about the Imagination, Imagination origin of the word Imaji / Imag, Image, latent images, images that are not visible, which was created by the efforts of Mental person, which can be used as learning techniques. The next test is a test of mental models mental model of the student's imagination. From the results of this research is that there 
are 15 students who have a mental model of the imagination. Through these tests the researchers found that the lack of students who experience mental models with imagination than the mental model of perception that is $17.04 \%$ of students who have a mental model of the imagination. It can be concluded that students in the test about this mental model that has a mental model of the imagination that is $17.04 \%$ of the students. The lecturers must to improve the student's imagination. At the time of teaching materials chemistry such abstract orbital, atomic forms, and other materials, it helps lecturers give an idea directly to the students so that the mental model of the imagination of students according to existing concepts ${ }^{[12,33]}$. Therefore the learning model that corresponds to increase mental models that use model student imagination non example/example learning. This learning model using images as a medium of learning in the delivery of learning materials aimed at encouraging students to learn to think critically to solve the issues contained in the examples of the images presented. The use of media image was conceived and designed to allow students to analyze images and language skills into a brief description of what is in the picture. So with this learning model can improve the mental model of the student's imagination.

\section{Profile students' discourse comprehension of atomic structure}

Discourse comprehension discourse is defined as the process of extracting meaning by a person of the written language. The results of this study are students did not understand the mental model tests discourse. It can be understood because the chemical found learning new words or unfamiliar to students, to the need to increase understanding of mental models of discourse, because the chemical material will be found new terms ${ }^{[27,33]}$. It is therefore expected to have a faculty instructional strategies to improve student mental models of discourse that inquiry strategy. Inquiry strategy is a series of learning activities that emphasize critical thinking and analysis process to search for and find their own answers on an issue that is questionable. This strategy is a form of learning-oriented approach to the students said that because of this strategy the student plays a very dominant in the learning process. So it can improve mental model student discourse.

\section{Research Findings}

From the analysis of research there are three students who had two mental models of perception and imagination. Due to mental models held by the students are expected to change because of its dynamic character. This gave rise to the dynamic nature of the new terminology that is purely mental models and mental models mix. Pure mental models that mental models are of yourself means understanding of a matter only came to him without mixing the knowledge that comes from others. This pure mental model of the students usually has only one mental model only. While the mental model is a mix of students who have more than one mental model of this is due to mixing of students understanding derived from various sources, this means that every human being has more than one mental model ${ }^{[33]}$. From the results of data analysis tests of mental models are $3.40 \%$ of students who have a mental model of perception and imagination. It can be concluded that the three students who have more than one mental model include having a double mental model.

\section{Conclusion}

The results of this research were positive; 1 . Mental model of perception has average value of 41.74 in moderate criteria. 2. Mental model of imagination has average value of 42.95 in moderate criteria. 3. Mental model of discourse comprehension has average value of 51.84 in moderate criteria. It shows that students' learning outcomes based on mental models of atomic structure in moderate criteria. Research findings is there are three students who had two mental models of perception and imagination. Due to mental models held by the students are expected to change because of its dynamic character. Limitation of this research as following: 1. Sample in this research was 32 student's chemistry learning of Mulawarman University, Samarinda, Indonesia. Future research can be more sample and another level and countries. 2. Learning outcomes based on mental models of atomic structure; other researches can improve this result.

\section{Acknowledgements}

This research has been supported by 2013 Mulawarman Univertsity Research Fund.

\section{References}

[1]. P.M. Senge, The fifth discipline. The art and practice of the learning organization (Doubleday Dell Publishing Group, Inc. New York, 2004).

[2]. M.A. Marks, S.J. Zaccaro, and J.E. Mathieu, Performance implications of leader briefings and team-interaction training for team adaptation to novel environments, Journal of Applied Psychology, 85, 2000, 971-986.

[3]. M.A. Marks, M.J. Sabella, C.S. Burke, and S.J. Zaccaro, The impact of cross-training on team effectiveness, Journal of Applied Psychology, 87, 2002, 3-13.

[4]. J.E. Mathieu, T.S. Heffner, G.F. Goodwin, J.A. Cannon-Bowers, and E. Salas, Scaling the quality of teammates' mental models: Equifinality and normative comparisons, Journal of Organizational Behavior, 26, 2005, 37-56. 
[5]. J.E. Mathieu, T.S. Heffner, G.F. Goodwin, E. Salas, and J.A. Cannon-Bowers, The influence of shared mental models on team process and performance. Journal of Applied Psychology, 85, 2002, 273-283.

[6]. J.R. Rentsch, and R.J. Klimoski, Why do 'great minds' think alike? Antecedents of team member schema agreement, Journal of Organizational Behavior, 22, 2001, 107-120.

[7]. K.A. Smith-Jentsch, J.E. Mathieu, and K. Kraiger, Investigating linear and interactive effects of shared mental models on safety and efficiency in a field setting, Journal of Applied Psychology, 90, 2005, 523-535.

[8]. R.J. Stout, J.A. Cannon-Bowers, E. Salas, and D.M. Milanovich, Planning, shared mental models, and coordinated performance: An empirical link is established, Human Factors, 41, 1999, 61-71.

[9]. S.S. Webber, G. Chen, S.C. Payne, S.M. Marsh, and S. J. Zaccaro, Enhancing team mental model measurement with performance appraisal practices, Organizational Research Methods, 3, 2000, 307-322.

[10]. J.A. Cannon-Bowers, E. Salas, and S. A. Converse, Cognitive psychology and team training: Shared mental models in complex systems. Human Factors Bulletin, 33, 1990, 1-4.

[11]. W.B. Rouse, and N.M. Morris, On looking into the black box: Prospects and limits in the search for mental models, Psychological Bulletin, 100, 1986, 349-363.

[12]. D.A. Norman, Some observations on mental models. (In D. Gentner, andA. L. Stevens (Eds.) Mental model. Hillsdale, NJ: Erlbaum, 1983).

[13]. E. Brunswik, Perception and the representative design of psychological experiments (Berkeley, CA: University of California Press, 1956).

[14]. K.B. McKeithen, J.S. Reitman, H.H. Rueter, and S.C. Hirtle, Knowledge organization and skill differences in computer programmers. Cognitive Psychology, 13, 1981, 307-325.

[15]. N.J. Nilsson, Learning machine, (McGraw Hill: New York, 1965).

[16]. J.R. Rentsch, and R. J. Hall, Members of great teams think alike: A model of team effectiveness and schema similarity among team members. Advances in interdisciplinary studies of work teams: Theories of self-managing work teams, 1, 1994, $223-261$.

[17]. K.Kraiger, E. Salas, and J.A. Cannon-Bowers, Measuring knowledge organization as a method for assessing learning during training, Human Factors, 37, 1995, 804-816.

[18]. A.L. Rowe, and N.J. Cooke, Measuring mental models: Choosing the right tools for the job. Human Resource Development Quarterly, 6(3), 1995, 243-255.

[19]. S. Mohammed, and B.C. Dumville, Team mental models in a team knowledge framework: Expanding theory and measurement across disciplinary boundaries. Journal of Organizational Behavior, 22, 2001, 89-106.

[20]. N. R. Herga, M. I. Grmek, and D. Dinevski, Virtual laboratory as an element of visualization when teaching chemical contents in science class, Turkish Online Journal of Educational Technology, 13(4), 2014, 157.

[21]. V. Gkitzia, S. Katerina, and T. Chryssa, Development and application of suitable criteria for the evaluation of chemical representations in school textbooks, Chem. Educ. Res. Pract, 12, 2011, 5-14.

[22]. B.Y. Guzel, and E. Adadan, Use of multiple representations in developing pre-service chemistry teachers' understanding of the structure of matter. International Journal of Environmental and Science Education, 8(1), 2013, 109-130.

[23]. L.Z. Jaber, and S. Boujaoude, A macro-micro-symbolic teaching to promote relational understanding of chemical reactions, International Journal of Science Education, 34 (7), 2012, 973-998.

[24]. R. Tasker, and R. Dalton, Research into practice: Visualization of the molecular world using animations, Chem. Educ. Res. Prac, 7, 2006, 141-159.

[25]. G.D. Chittleborough, and D.F. Treagust, The modeling ability of non-major chemistry students and their understanding of the sub-microscopic level, Chem. Educ. Res. Pract, 8, 2007, 274-292.

[26]. R.K. Coll, Chemistry learners' preferred mental models for chemical bonding, Journal of Turkish Science Education, 5 (1), 2008, $22-47$.

[27]. B. Eilam, and Y. Poyas, External visual representations in science learning: The case of relations among system components, International Journal of Science Education, 32(17), 2010, 2335-2366.

[28]. V.Prain, R. Tytler, and S. Peterson, Multiple representation in learning about evaporation, International Journal of Science Education, 31(6), 2009, 787-808.

[29]. K.J. Schönborn, and T.R. Anderson, A model of factors determining students' ability to interpret external representations in biochemistry, International Journal of Science Education, 31(2), 2009, 193-232.

[30]. I. Devetak, D.L. Erna, J. Mojca, and S.A. Glažar, Comparing slovenian year 8 and year 9 elementary school pupils' knowledge of electrolyte chemistry and their intrinsic motivation, Chem. Educ. Res. Pract., 10, 2009, 281-290.

[31]. B. Davidowitz, G.D. Chittleborough, and M. Eileen, Student-generated submicro diagrams: A useful tool for teaching and learning chemical equations and stoichiometry, Chem. Educ. Res. Pract., 11, 2010, 154-164.

[32]. R.A. McBroom, Pre-service science teachers“ mental models regarding dissolution and precipitation reactions, (Doctoral dissertation, North Carolina State University. Raleigh, North Carolina, 2011).

[33]. Sunyono, and Yulianti, D. Introductory study on student's mental models in understanding the concept of atomic structure (Case study on high school students in Lampung Indonesia). The Online Journal of New Horizons in Education, 5(4), 2015, 41-50. 